\section{BASIC subroutines for on-line experiments using Hewlett-Packard computers*}

\author{
WILLIAM J. RAY \\ Langley Porter Neuropsychiatric Institute, San Francisco, California 94122 \\ and \\ JAMES H. HOGGE† \\ George Peabody College, Nashville, Tennessee 37203
}

Modifications of the Hewlett-Packard version of the BASIC language to permit its use in data acquisition and control of on-line experiments are described. The resulting software system is an easy-to-use interpretative compiler.

Although computer programs for the control of experiments and the acquisition of data may be developed using Assembly language, this approach restricts potential users to those individuals either facile in the language or dependent upon a programmer; moreover, Assembly language program development on small computer systems without magnetic tape or disk storage is tedious and time consuming. On the other hand, BASIC, as implemented on Hewlett-Packard systems, is a relatively easy-to-learn mathematical language. Because BASIC operates as an interpretative compiler, the user's program is core resident and may be modified from the system teleprinter. While BASIC is much less efficient than Assembly language with respect to core requirements and execution speed, we have found it to be adequate for the levels of program complexity and data rates associated with the real-time analysis of such bioelectrical

*This research is part of the program of the John F. Kennedy Center for Research on Education and Human Development, George Peabody College for Teachers, Nashville, Tennessee, under a Biomedical Sciences Support Grant from the National Institutes of Health. This research was supported also by NIMH Grant No. 5-R12,16250, Hans H. Strupp, principal investigator. The assistance of the Hewlett-Packard Company in creating the source code for several of the subroutines described is gratefully acknowledged.

tRequests for reprints and information concerning the availability of the subroutines should be sent to James $H$. Hogge, Box 512, George Peabody College, Nashville, Tenessee 37203. signals as heart rate, respiration, and EEG.

Modification of Hewlett-Packard BASIC for use with on-line experiments was accomplished through the addition of Assembly language subroutines as described in $A$ guide to HP educational BASIC (1970). These subroutines, accessed from BASIC by means of a CALL statement, allow the user to (1) time segments of an experiment, using up to four software "clocks," (2) control the opening and closing of 16 relays, (3) accept readings from an analogue-to-digital converter, and (4) test the console switch register to determine if a sense switch is on or off.
Each subroutines is referenced via a CALL statement of the general form

$$
S \operatorname{CALL}\left(\mathrm{N}, \mathrm{P}_{1}, \mathrm{P}_{2}, \ldots \mathrm{P}_{\mathrm{K}}\right)
$$

where $S$ is a statement number, $N$ is the subroutine number, and $P_{1}$ through $\mathbf{P}_{\mathrm{K}}$ are parameters. For example, the statement

$$
190 \text { CALL }(10, X(1), N)
$$

would cause the computer to read $\mathrm{N}$ values (where $\mathrm{N}$ had previously been defined) from the analogue-to-digital converter and store the values in the array $\mathrm{X}$ beginning with $\mathrm{X}(1)$.

Table 1 contains descriptions of the

most frequently used subroutines.

Required hardware and corresponding Hewlett-Packard model numbers are as follows: any Hewlett-Packard computer with 8,192 words of core storage, teleprinter (2752A/12531C or $2754 \mathrm{~B} / 12531 \mathrm{C}$ ), time base generator $(12539 \mathrm{~B})$, relay output register (12551B), and analogue-to-digital converter (12564A).

\section{REFERENCE}

HEWLETT-PACKARD. A guide to $H P$ educational BASIC. Cupertino, Calif: Hewlett-Packard, 1970, Manual HP $02116-91773$

Table 1

\begin{tabular}{|c|c|}
\hline CALL Statement & Function \\
\hline $\begin{array}{l}\text { CALL }(3, H, M, S) \\
\text { CALL }(4, N)\end{array}$ & $\begin{array}{l}\text { Tests switch register switch number } S \text { : if } X=-2 \text {, the } \\
\text { switch is on; if } X=1 \text {, the switch is off. If } S \text { is set } \\
\text { equal to }-1 \text {, all switches are cleared. } \\
\text { Starts the clock and initializes the time of day at } H \text {, } \\
M \text { min, and } S \text { sec. } \\
\text { Reads the time of day in hours, minutes, and seconds. } \\
\text { Initializes an integer counter at and causes it to be } \\
\text { incremented by } 1 \text { every }(N * 1 \phi) \text { milliseconds. }\end{array}$ \\
\hline $\begin{array}{l}\text { CALL (5, N) } \\
\text { CALL (13) }\end{array}$ & $\begin{array}{l}\text { A ssigns the value of the integer counter to } N \text {. } \\
\text { Starts a second counter with increment rate set by } \\
\text { CALL ( } 4, N) \text {. }\end{array}$ \\
\hline $\begin{array}{l}\text { CALL (15) } \\
\text { CALL (14, N) } \\
\text { CALL }(16, N) \\
\text { CALL (6) } \\
\text { CALL (7. N) }\end{array}$ & $\begin{array}{l}\text { Starts a third counter with increment rate set by CALL }(4, N) \text {. } \\
\text { Reads the second timer. } \\
\text { Reads the third timer. } \\
\text { Opens all relay contacts. } \\
\text { Closes relay contact } N \text {. }\end{array}$ \\
\hline $\begin{array}{l}\text { CALL }(8, N) \\
\text { CALL }(9, X) \\
\text { CALL }(1, \times(1), N)\end{array}$ & $\begin{array}{l}\text { Opens relay contact } N \text {. } \\
\text { Reads one value from the analogue-to-digital converter. } \\
\text { Reads } N \text { values from the analogue-to-digital converter and } \\
\text { stores them in the array } X \text {, beginning with } X(1) \text {. }\end{array}$ \\
\hline
\end{tabular}

BASIC Subroutines 